First Peoples Child \& Family Review

An Interdisciplinary Journal Honouring the Voices, Perspectives, and Knowledges of

First Peoples through Research, Critical Analyses, Stories, Standpoints and Media

Reviews

\title{
Residential Schools: Creating and Continuing Institutionalization among Aboriginal Peoples in Canada
}

\section{Julia Rand}

Volume 6, Number 1, 2011

URI: https://id.erudit.org/iderudit/1068896ar

DOI: https://doi.org/10.7202/1068896ar

\section{See table of contents}

\section{Publisher(s)}

First Nations Child and Family Caring Society of Canada

\section{ISSN}

1708-489X (print)

2293-6610 (digital)

Explore this journal

Cite this article

Rand, J. (2011). Residential Schools: Creating and Continuing

Institutionalization among Aboriginal Peoples in Canada. First Peoples Child \&

Family Review, 6(1), 56-65. https://doi.org/10.7202/1068896ar
Article abstract

Many Aboriginal peoples in Canada have experienced, directly or indirectly, the effects of residential schools. Some Aboriginal people have also experienced the phenomenon known as institutionalization, as a result of residential school experiences, experiences over which they had no control and that were demanded by law. Some Aboriginal people in Canada have moved from the residential school institutions to similar newly developed institutions such as shelters and to established institutions such as the correctional system, or both. Indeed, Aboriginal peoples are overrepresented in all such institutions. In this paper, I seek to demonstrate the association between Aboriginal peoples' experiences in and of residential schools and subsequent adult institutionalization. Attempts to 'civilize' Aboriginal peoples through cultural assimilation may have instead resulted in intergenerational institutionalization among many Aboriginal peoples in Canada.
This document is protected by copyright law. Use of the services of Érudit (including reproduction) is subject to its terms and conditions, which can be viewed online.

https://apropos.erudit.org/en/users/policy-on-use/ 


\section{First Peoples Child \& Family Review}

An Interdisciplinary Journal Honoring the Voices, Perspectives and Knowledges of First Peoples through Research, Critical Analyses, Stories, Standpoints and Media Reviews

\section{Residential Schools: Creating and Continuing Institutionalization among Aboriginal Peoples in Canada}

Julia Randa

a Bachelor of Social Work, University of Calgary; Master of Social Work Student, Faculty of Social Work, University of Calgary, Alberta.

\section{Introduction}

According to a variety of sources, Aboriginal peoples are overrepresented in a variety of modern day institutions. To increase our understanding of why this phenomenon has occurred, it is useful to review the history of residential schools and the nature of those now-defunct institutions. Furthermore, it is helpful to consider the reasons residential schools, and similar institutions, developed the way they did. Considering Goffman's (1961) notion of the Total Institution leads to a better sense of how institutionalization and re-institutionalization occur and how the consequences of these processes to Aboriginal peoples have played out over the decades.

\section{A Brief History of Residential Schools}

The colonization of North America started in the seventeenth century which saw increasing numbers of Europeans arriving in both what is now Canada and the United States (Titley, 1986). Colonization is an act predicated on a mindset of

Questions or correspondence concerning this article may be addressed to:

Email: jrand@ucalgary.ca

\begin{abstract}
Many Aboriginal peoples in Canada have experienced, directly or indirectly, the effects of residential schools. Some Aboriginal people have also experienced the phenomenon known as institutionalization, as a result of residential school experiences, experiences over which they had no control and that were demanded by law. Some Aboriginal people in Canada have moved from the residential school institutions to similar newly developed institutions such as shelters and to established institutions such as the correctional system, or both. Indeed, Aboriginal peoples are overrepresented in all such institutions. In this paper, I seek to demonstrate the association between Aboriginal peoples' experiences in and of residential schools and subsequent adult institutionalization. Attempts to 'civilize' Aboriginal peoples through cultural assimilation may have instead resulted in intergenerational institutionalization among many Aboriginal peoples in Canada.

Keywords: Residential Schools; child welfare and correctional systems; family violence; Aboriginal women; intergenerational institutionalization.
\end{abstract}

cultural superiority. Members of one culture view themselves - their own culture, worldview, norms, values and beliefs - as superior to members of another culture. The establishment of residential schools may be seen as an extension of the act of colonization.

Residential schools were built and operationalized in Canada after the federal government reviewed the policy known as "aggressive civilization", originally developed in the United States (Davin, 1879, p. 1). European colonizers in both countries experienced culture clashes with the indigenous inhabitants. These clashes intensified as members of the colonies 
increased in numbers and moved west (Titley, 1986). The policy was intended to assimilate Aboriginal people into the newly developing agrarian way of life. Assimilation was difficult because European settlers were encouraged to settle land already occupied by Aboriginal peoples living a nomadic, hunter-gatherer way of life. In order to vacate and assume ownership of the land, the American government created Indian reservations and opened industrial boarding schools (Brave Heart, 2000). In both countries, these actions resulted in the removal of Aboriginal peoples from the land which in turn enabled farmers to homestead and to establish settlements (Fournier \& Crey, 1997).

According to the Royal Commission on Aboriginal Peoples [RCAP], Nicholas-Flood Davin, a Member of Parliament for the Conservative government, was directed by the government to tour the United States to learn about that country's approach to dealing with 'the Indian problem' (1996). In his "Report on Industrial Schools for Indians and Half Breeds" (1879, p. 1 ), Davin identified industrial boarding schools as the "principle feature" of the policy of "aggressive civilization" which had been developed specifically to deal with what was identified as 'the Indian problem' in the United States. Industrial boarding schools in that country were primarily intended to assimilate Aboriginal children into the new American social order by providing them with the basics of an English education and training in both agriculture and skilled trades for boys and homemaking for girls (Davin, 1897). The Davin Report provided the basis for a proposal for the implementation of industrial boarding schools for boys. The final decision was to implement residential schools and children of both genders were required by law to attend. Both Canadian and American institutions shared the objective of "rapid assimilation" of Aboriginal children into the dominant social order (Enns, 2009, p. 117).

Once committed to this course of action, the financial costs of running these institutions became a major concern to the federal government. To keep costs down, the federal government handed over responsibility for daily operations of residential schools to the established churches of the day. According to the RCAP (1996), Catholic, Anglican, Presbyterian, and Methodist (later, with other denominations, to become the United Church of Canada) clergy, motivated to convert Aboriginal peoples to Christianity, assumed responsibility for operations of these institutions at the request of the federal government.

The Canadian solution differed somewhat from the American solution insofar as, in Canada, residential schools were funded by the federal government but operated by churches. The federal government, "pressured by British homesteaders who demanded ... [that] Indians be neutralized or removed from the land" supported "religious-run boarding schools for Indian children" (Fournier \& Crey, 1997, p. 53). The Assembly of First Nations [AFN] maintains that the "acceptance of the Davin Report formalized the policy of assimilation in a systematic and all-encompassing way through the implementation of residential schooling and a cooperative relationship between "church and state"" (1994, p. 14).

Inherent in the concept of residential schools is the assumption of the acceptability of political violence against Aboriginal peoples, given the requirement that children be removed from their families in order to be placed in these schools, removed by force if necessary. The notion of political violence is applicable to the residential school experience in that it constitutes "those acts of an intergroup nature that are seen by those on both sides, or on one side, to constitute violent behaviour carried out in order to influence power relations between the two sets of participants" (Cairns, 1996, as cited in Weingarten, 2007, p. 55). Together, church and state in Canada exercised near absolute power over the lives of Aboriginal peoples, and in particular, over the lives of their children.

The residential school system provided the government with a critically important tool to use in working towards its objective of cultural assimilation. The government's "official policy called for children to be isolated not only from their 
family and homelands but also, once at school, from their friends and siblings" (Fournier \& Crey, 1997, p. 56). From their inception, residential schools were operated by non-Aboriginal staff. Cultural assimilation and religious indoctrination were to be accomplished by increasing a child's vulnerability through isolation.

The objectives of religious indoctrination and cultural assimilation were realized through daily activities which followed a strict regimen of labour and routine (Fournier \& Crey, 1997). All activities associated with daily living followed a strict schedule. A former student of residential school describes the school activities as "regimental ... it was like what I imagine jail to be" (Jaine, 1993, p. 11). Fournier and Crey note the urgings of a federal report which stated "there should be an object for employment of every moment" (1997, p. 56), similar to the expression that "the devil finds work for idle hands.' At residential schools, children were forbidden from speaking their native languages and from practicing traditional ceremonies (AFN, 1994). Aboriginal peoples, like those the world over, articulate their ways of knowing in their own unique languages. Since language reflects and reinforces culture and culture reflects and reinforces language, denying children their language was instrumental in the objective of the eradication of Aboriginal culture.

By the late 1940's "four or five generations had returned from residential schools as poorly educated, angry, abused strangers who had no experience in parenting" (Fournier \& Crey, 1997, p. 82). As a result, residential schools were ostensibly transformed during the 1950's from institutions created to assimilate to institutions acting in loco parentis.

According to the AFN (1994), residential schools underwent three historical shifts during their operations. During phase one, these institutions were focused on assimilation and religious conversion while preparing Aboriginal children for a place in the lowest echelons of the economy. During the second phase, the intent was to prepare children to return to their communities, taking with them their new European language and training with a view to introducing change from within to traditional Aboriginal communities. Phase three saw another shift in emphasis which aimed to integrate Aboriginal children into mainstream society by the introduction of programming that was much more in line with that found in mainstream schools. The last residential schools were not closed until the last decades of the twentieth century.

Generations of Aboriginal peoples were abused physically, emotionally, sexually, and spiritually while attending residential schools in Canada. Significant numbers of former residential school staff have plead guilty to charges of psychological, spiritual, sexual and physical abuse they committed against Aboriginal children residing in those institutions (RCAP, 1996). The federal government acknowledged the abuses suffered by Aboriginal peoples by issuing a formal, public apology in 2008. This acknowledgement, along with the negotiation of a $\$ 2$ billion classaction settlement for residential school survivors and the creation of the Indian Residential Schools Truth and Reconciliation Commission, solidified the reality of the horrific acts carried out in residential schools (Diebel, 2009, March 16).

\section{Residential Schools Assuming Parental Roles}

In families, primary caregivers tend to be parents. In residential schools, primary caregivers were the clergy and members of religious societies who were priests and nuns. Those very staff members who committed horrific acts against Aboriginal children assumed a parental role within residential schools on behalf of church and state.

Parenting can be viewed as an institution insofar as it is "a complex of values, beliefs, norms and behaviours centred in . . . the need to care for the young" (LaRossa, 1986, p. 11). Simply put, the parental role can be viewed as having three primary dimensions. The physical wellbeing of the child is the responsibility of the 
parent as guardian or custodian. The spiritual, cultural and intellectual well being of the child is fostered by the parent as teacher and mentor. The child's sense of self as a being of worth and value, is reinforced by a parent's love, affection, and support. Involvement in a healthy community is beneficial for parents and families to successfully achieve these tasks.

In Aboriginal communities, children were highly valued and placed "at the heart of a belief system closely aligned with the natural world" (Fournier \& Crey, 1997, p. 52). Traditional Aboriginal societies relied on an oral tradition for both the transmission of their beliefs, values, norms and behaviours and the transmission of knowledge of the physical world, fauna, flora, climate, astronomy etc. In traditional Aboriginal societies, the survival of the community depended on their oral tradition and the ability of children to successfully transition into the next generation of custodians of that oral tradition (AFN, 1994).

The ultimate indication of successful parenting in traditional Aboriginal communities was the survival and success of the community. According to Titley (1986) the goal of residential schools was three fold: the eradication of Native languages to be replaced with English, the replacement of Aboriginal spirituality with Christianity, and the assimilation of Aboriginal peoples into the dominant culture. The parental role of staff in residential schools included activities which, on the surface, were similar to those of Aboriginal parents but were directed at achieving very different objectives. Residential school staff assumed custodial roles with the intent of exercising complete control over children's actions and severely limiting their independence of movement. Staff in a mentoring role attempted to instil in children churchsanctioned norms, values and beliefs to replace those of traditional cultures. They assumed the role of educator with the objective of replacing children's traditional knowledge and ways of knowing with those in line with the dominant culture. Finally, staff also instilled a sense within the child that his or her role was not to be a full member of an Aboriginal community but rather to be a member of the lower strata of society serving the dominant culture (Titley, 1986).

Clearly, based on this comparison of parental roles and objectives between Aboriginal parents and residential school staff, it is evident that staff generally assumed an extremely authoritarian, negative, and uncaring stance. "The missionaries, who essentially became substitute parents, did not provide the nurturing required for the development of positive self-worth and selfesteem or the ability to feel good about one's self" (AFN, 1994, p. 39). These institutions and their staff were highly inadequate replacements for children's rightful parents and grandparents. As indicated, parenting is not simply the passing on of knowledge, values and beliefs. The dimensions of nurturing and affection which underpin and infuse the transmission of culture in Aboriginal communities strengthen immeasurably both that transmission and the community. It is critical for a parent to provide a child with a mirror reflecting the child's value, importance, and sense of belonging to the family and the community. These essential aspects of parenting were absent from residential schools.

After isolating children from their families, further isolating them from friends and family within the institution and working to destroy their cultural identity, residential school staff then acted as surrogate families, albeit families characterized by significant dysfunction. The indoctrination of Christian religious beliefs coupled with Eurocentric cultural teachings created an identity crisis among many residential school survivors (Johnston, 1998).

\section{The Total Institution}

Goffman (1961) was the first researcher to conceptualize and articulate the notion of the Total Institution. The objective of the Total Institution is to destroy the ability of the institutionalized individual to fully achieve selfhood, to become an autonomous, self-actualized human being. Achieving this objective enables the Total 
Institution to achieve its own institutional objectives which are generally associated with a political ideology. One important objective is the destruction of the individual's own cultural identity and its replacement with an identity closely tied to the institution.

A Total Institution is associated with a number of characteristics, a brief description of which follows. The Total Institution is characterized by its physical isolation from the community. Within the institution's physical structure, the elimination of the association between a role and a physical place where that role is played out is achieved. There is an extreme power differential between the inmates and the staff. Inmates are cut off from the outside world but staff continue to be integrated with the outside world.

A number of actions are taken against inmates to achieve the overall objective of the Total Institution. One set of actions focuses on an individual's possessions. Upon entering the institution, individuals are stripped of their own clothing and possessions which are replaced by goods provided by the institution. All goods, including clothing, tend to be identical which further erodes any sense of individuality. Another set of actions is focused on the body of the individual. He or she is subject to extreme cleansing, often including disinfecting, given standard haircuts, issued with an identification number and so on. Physical and sexual abuse may also occur. The next set of actions focuses on the elimination of the individual's social structure. There may be the potential for remnants of the individual's existing social structure to be rebuilt within the institution and this potential is destroyed. A last set of actions focuses on the elimination of the multiplicity of roles which characterizes life outside the institution and its replacement with the single role of inmate.

It is highly likely that anyone who has experienced life within a total institution on a long term basis will experience difficulty in taking up his or her role within the wider society upon release. Chrisjohn and Young (1997, p. 73) maintain that the "total institution does not produce a new self but no self at all." A person who has become institutionalized often experiences a highly eroded, degraded or complete loss of personal identity. Reduced interest in the outside world, lost interpersonal relationships with individuals outside the institution, and diminished perceptions of personal abilities and personal agency for independent decision-making are correlated with long term residency in authoritarian institutions (Crawley \& Sparks, 2006). Adjustment to life outside the institution can be difficult, given that, after spending years following strictly regimented daily schedules, that structure is suddenly absent.

Given similar experiences within a Total Institution, many individuals, after release, may exhibit similar behaviours. Individuals tend to gravitate towards what they know, towards what is familiar. After a long period of time in a Total Institution, what is familiar includes the expectation of externally-imposed regimentation and structure, the loss of personal identity, and the feeling of worthlessness. Such individuals may tend to gravitate towards the same or another Total Institution environment after having developed an institutional memory (Sider, 2005). It is critical to note that this is the case regardless of ethnicity, gender, religion, age, social status or other characteristics. Children experiencing a Total Institution during their formative years are likely to be even more damaged than adults.

If a mode of circular causality (Collins, Coleman \& Collins, 2005) is adopted, institutionalization can be interpreted as a repetitive, circular pattern which is negatively reinforced. These traumatic experiences of isolation, institutionalization, and abuse coupled with the detachment from family and culture, create negative patterns of behaviour which may ultimately result in the re-institutionalization of many adults and subsequently of their children.

\section{Residential School as Total Institution}

As described in the first section of this paper, residential schools exhibited many of the 
characteristics identified by Goffman (1961) as being associated with Total Institutions. Actions taken against Aboriginal children entering and living in residential schools are consistent with actions taken against inmates in Total Institutions. Therefore it is reasonable to identify residential schools as total institutions.

Why is it important to identify residential schools as Total Institutions? When an Aboriginal person who has experienced residential school rejoins the community, that person will likely experience difficulty in assuming his or her role within that community and within the wider society. For example, a former residential school student recalls:

After the ten years I spent in residential school there were a lot of adjustments to be made.

The church was no longer the focal point of my life ... I wanted so much to be free and to do the things I had heard about and seen other people do. I wanted to do those things too, and I did them, but I couldn't handle the freedom. (Jaine, 1993, p. 63)

As indicated previously, like any former inmate of a Total Institution, many individuals who have experience of residential schools may gravitate towards that which is familiar. This tendency to gravitate towards the familiar may provide one explanation, among a number, as to why such individuals are found in disproportionate numbers in various types of institutions. The reactions of an Aboriginal person having experienced a Total Institution, such as a residential school, are likely to be the same as any other person with that experience.

Long term impacts of living within the context of a Total Institution may include a loss of personal identity and autonomy and, as mentioned previously, the creation of an institutional memory (Sider, 2005). Individuals who are taught/conditioned as children to obey without question the rules of an institution may, in turn, come to identify with and subsequently depend on this type of environment. As adults, they may experience significant difficulties in terms of parenting, seeking and maintaining employment, finding housing, and accessing other support services. Individuals who continuously experience these kinds of difficulties may ultimately develop a dependency on social services and correctional institutions (Sider, 2005).

Through the lens of the Total Institution, it is reasonable to propose that the overrepresentation of Aboriginal peoples within social service and correctional institutions may, in part, be a result of Aboriginal peoples moving to present. day institutions from the historic institution of residential schools. It may be argued that many Aboriginal peoples have been conditioned to life in institutional settings. That is to say, a new identity has overlaid the original identity, one which is more consistent with institutional culture than with traditional culture. The next sections provide information which supports this view.

\section{Aboriginal Peoples and Correctional Institutions}

As colonizer, the government's agenda was to eradicate Aboriginal culture in favour of its own so-called superior culture using the institution of residential schools. The methods used to carry out this agenda have left many Aboriginal Peoples with significant feelings of rage. "Aboriginal Peoples are being re-victimized by colonization this time indirectly as colonization is turned inside out by Aboriginal Peoples victimizing themselves and where women and children bear the brunt of such trauma" (Chartrand \& Mackay, 2006, p. 6). One consequence is that, while Aboriginal peoples accounted for only $3.1 \%$ of the Canadian adult population, they made up $18 \%$ of the population in provincial and territorial custody" (Statistics Canada, 2009, para 19).

Family violence, alcoholism and suicidal behaviour among Aboriginal peoples, according to Gagne (1998), can be directly or indirectly related to abuses they suffered as children at residential school. Chartrand and Mackay (2006, p. 47) contend that "society's response to dealing 
with the trauma experienced by abused Aboriginal individuals and the consequential effects has often been to institutionalize the affected individuals in prisons and other institutions", essentially punishing the victim. According to Brzozowski, Taylor-Butts and Johnson (2006), Aboriginal people made up $10 \%$ of the general population in Saskatchewan yet they comprised $80 \%$ of adults in provincial custodial facilities; $11 \%$ of the general population in Manitoba were Aboriginal and comprised $68 \%$ of the province's incarcerated population; $4 \%$ of Alberta's general population were Aboriginal and $39 \%$ of its provincial prison population were Aboriginal. "In other provinces and territories the proportion of Aboriginal peoples in custody ranged from two to six times their proportional representation in the general population" (Brzozowski, et al., 2006, p. 13). These statistics are consistent with the findings of both Gagne (1998) and Chartrand and Mackay (2006). Clearly, Aboriginal peoples are overrepresented in correctional institutions and the impetus is likely to start with the process of re-institutionalization.

\section{Aboriginal Peoples and Family Violence}

As noted previously, the majority of family violence can be related to abuses many Aboriginal peoples experienced as children in residential schools (Gagne, 1998). According to Weingarten (2004), therapists generally accept that children of parents suffering from chronic post-traumatic stress disorder caused by political violence may well be affected by the experiences of their parents. Problems that these families experience may be linked to political events of long ago, events which have no apparent association with the current situation. As indicated in the first section of this paper, what was essentially imprisonment in residential schools was indeed a form of political violence. Weingarten (2004, p. 45) further describes "the belief that a family member who has experienced trauma can 'expose' another member to 'residues' of that trauma, even though the exposed family member does not directly experience that trauma." There can be intergenerational and multigenerational transmissions of trauma (Brave Heart, 2000). Fournier and Crey (1997) also agree that former residential school students and their own children and grandchildren experience intergenerational trauma.

Rates of sexual assault and other violent crimes are reported to be higher on reserves than in other areas of Canada (Statistics Canada, 2006). One in five Aboriginal people indicated that they had experienced spousal violence from a current or previous partner; in comparison with fewer than one in fifteen non-Aboriginal people (Brzozowski, et al., 2006). Rates and severity of spousal violence are higher for Aboriginal women than for non-Aboriginal women (Statistics Canada, 2006).

\section{Aboriginal Women and Battered Women's Shelters}

A study conducted by Taylor-Butts (2003/04) found that $64 \%$ of women's shelters across Canada provide culturally-sensitive programming designed for Aboriginal women. Provision of these services supports the assumption that a significant number of Aboriginal women require services from these institutions. The Alberta Council of Women's Shelters [ACWS] reported in 2009 that Aboriginal women are at higher risk for experiencing domestic violence than other cultural groups, that they are generally overrepresented within battered women's shelters and that this is a consistent pattern over a number of years.

Aboriginal women make up $81 \%$ of shelter residents in northern Alberta, $60 \%$ in central Alberta, and $28.7 \%$ in the southern region of the province (ACWS, 2009). Women seek shelter in and are admitted to these institutions largely because they have been victims of domestic violence. Domestic violence among Aboriginal people is either directly or indirectly associated with abuse they experienced or witnessed at residential school (Gagne, 1998). 


\section{Aboriginal Peoples and Child Welfare}

Child welfare, while not having a physical location like a jail or a shelter, does exhibit some of the characteristics associated with a Total Institution. A Total Institution is characterized by isolation from the community. A child taken into care will likely be isolated from his or her community while parents of an apprehended child are forced to deal with child welfare staff, generally outside the community, as opposed to seeking guidance from Aboriginal Elders and members of the Aboriginal community. A Total Institution is characterized by an extreme power differential between staff and inmates. In the child welfare system, there is an extreme power differential between parents and child welfare staff. Parents involved with child welfare must demonstrate their competencies as parents to child welfare staff who ultimately decide whether or not their child should be apprehended and placed into state care. While systemic racism and discrimination certainly play a role in the overrepresentation of Aboriginal children within the child welfare system, residential school experiences of parents and grandparents within Total Institutions may also play a role in the disproportionate number of Aboriginal children in state care.

While the population of residential schools was completely disproportionate given that the population was exclusively Aboriginal, Aboriginal children continue to be disproportionately represented within child welfare systems across Canada. The Canadian Broadcasting Corporation [CBC] reported in November of 2009 that one in ten children in state care are Aboriginal. In that same year, Laurie Monsebraaten, a reporter with the Toronto Star, reported that more Aboriginal children "are in the care of children's aid societies today than were forced to live in residential schools." In that same report, Monsebraaten estimated that 27, 000 Aboriginal children were living in foster care across the country (2009, November 22). It is interesting to note that, while residential school staff usurped the role of parent in the 1800s and 1900s, the child welfare institution and staff have been viewed as usurping the parental role in Aboriginal families as child welfare gradually replaced residential schools over the latter half of the twentieth century. The tragedy of the remove of children from Aboriginal parents which first started with residential schools is often repeated with the actions of child welfare staff.

\section{Conclusion}

The information presented in this paper demonstrates an association between residential school experiences and the re-institutionalization of Aboriginal adults. Further, it is clear that the overrepresentation of Aboriginal peoples within modern institutions also has an association with the residential school experience. It is likely that re-institutionalization and overrepresentation are linked. As shown by the discussion of the concept of the Total Institution, Aboriginal peoples are by no means unique in their lived consequences of experiencing the Total Institution and any notion that Aboriginal peoples are responsible for their own victimization is groundless. With respect to these consequences which include loss of personal identity, intergenerational trauma, increased violence etc., as Chrisjohn and Young (1997) make clear, there is no mystery, no need to obfuscate in a fog of misplaced compassion. There is a chain of cause and effect, outcome and accountability, the clarity of which becomes clearer over time as attention is focused on the history and aftermath of residential school institutions. Chair of the Indian Residential Schools Truth and Reconciliation Commission, Justice Murray Sinclair encouraged healing among Aboriginal peoples and acknowledges the destructive nature of residential school institutions imposed upon them:

Our families were broken ... and must be rebuilt. Our relationships have been damaged and must be restored. Our spirits have been stolen and must be returned. Our love of life was turned to fear and we must 
work together to learn to trust once again. (CBC, 2009, October 15)

Many Aboriginal people and their communities have begun processes of healing in which traditional cultures have played and continue to play an instrumental and integral role. However, many individuals are still lost. Aboriginal peoples across Canada have displayed courage, resilience, tenacity and strength in their ongoing commitment to bring to light in the broader Canadian context the reality of their experiences. It is the responsibility of all Canadians to understand the oppressive nature and the historical attempts of the federal government to assimilate Aboriginal peoples through its implementation of Indian residential school institutions.

\section{References}

Alberta Council of Women's Shelters. (2009, June). Executive summary: Keeping women alive - assessing the danger. Retrieved from http://www.acws.ca/ documents/KeepingWomen Alive.pdf.

Assembly of First Nations. (1994). Breaking the silence: An interpretive study of residential school impact and healing as illustrated by the stories of First Nations individuals. Ottawa, Canada: Assembly of First Nations.

Brave Heart, M. Y. (2000). Wakiksuyapi: Carrying the historical trauma of the Lakota. Tulane Studies in Social Welfare, 21(22), 245-266. Retrieved from http://discoveringourstory.org/ht_and_grief/ Wakiksuyapi-HT.pdf.

Brzozowski, J., Taylor-Butts, A., \& Johnson, S. (2006). Victimization and offending among the Aboriginal population in Canada. Juristat Canadian Centre for Justice Statistics, 26(3), 1-31. Retrieved from http:// dsp-psd.pwgsc.gc.ca/Collection-R/Statcan/85. 002-XIE/85-002-XIE2006003.pdf

Chartrand, L., \& Mackay, C. (2006). A review of research on criminal victimization and First Nations, Métis and Inuit people 1990 to 2001. Policy Centre for Victims Issues, Research and Statistics Division. Retrieved from http://www.justice.gc.ca/eng/pi/rs/reprap/2006/rr06_vic1/rr06_vic1.pdf.

Chrisjohn, R., \& Young, S. (1997). The circle game. Penticton, BC: Theytus Books Ltd.
Collins, D., Coleman, H., \& Collins, T. (2005). Family systems theory. In D. Collins, H. Coleman, \& T. Collins, Family practice: A problem-based learning approach (pp. 105-132). Peosta, IA: Eddie Bowers Publishing Company.

Crawley, E., \& Sparks, R. (2006). Is there life after imprisonment?: How elderly men talk about imprisonment and release. Criminology and Criminal Justice, 6, 62.82. doi: 10.1177/1748895806060667.

Davin, N.F. (1879, March 14). Report on Industrial Schools for Indians and Half Breeds. (Microform CIHM_03651[1].pdf). Canadian Institute for Historical Microreproductions [1980]. Retrieved from http://www.archive.org/details/cihm_03651.

Diebel, L. (2009, March 16). Nation of lost souls. The Toronto Star. Retrieved from http://www.thestar. com/News/Canada/article/602846

Enns, R. A. (2009). "But What Is The Object Of Educating These Children, If It Costs Their Lives To Educate Them?": Federal Indian education policy in Western Canada in the late 1800s. Journal of Canadian Studies, 43(2), 101-123. Retrieved from http://muse.jhu.edu/journals/jcs/

Fournier, S., \& Crey, E. (1997). Stolen from our embrace: The abduction of First Nations children and the restoration of Aboriginal communities. Vancouver, BC: Douglas and Mclntyre, Inc.

Gagne, M. (1998). The role of dependency and colonialism in generating trauma in First Nations citizens. In Y. Danieli (Ed.), International handbook of multigenerational legacies of trauma (pp. 355-372). New York: Plenum Press.

GG relaunches Truth and Reconciliation Commission. (2009, October 15). Canadian Broadcasting Corporation. Retrieved from http://www.cbc.ca/ news/canada/story/2009/10/15/indian-truthcomission015.html.

Goffman, E. (1961). Asylums: Essays on the social situation of mental patients and other inmates. Chicago, IL: Aldine Publishing Co.

Jaine, L. (1993). Journeys. In L. Jaine (Ed.), Residential schools: The stolen years (pp. 8-22). Saskatoon, Sask: University Extension Press, University of Saskatchewan.

Johnston, B. H. (1998). Indian school days. Toronto, Ont: Key Porter Books Limited.

LaRossa, R. (1986). Becoming a parent. Beverly Hills, CA: Sage Publications. 
First Peoples Child \& Family Review, Volume 6, Number 1, 2011

Monsebraaten, L. (2009, November 23) Native children flooding into children's aid societies. The Toronto Star. Retrieved from http://www.parentcentral. ca/parent/newsfeatures/article/729140--nativechildren-flooding-into-children-s-aid-societies.

Royal Commission on Aboriginal Peoples. (1996). Report of the Royal Commission on Aboriginal Peoples: Looking forward, looking back, Volume 1, Part 2: False assumptions and a failed relationship. Ottawa: Canada Retrieved from http://caid.ca/RRCAP1.10. pdf.

Sider, D. (2005). A sociological analysis of root causes of Aboriginal homelessness in Sioux Lookout, Ontario. The Canadian Race Relations Foundation. Retrieved from http://www.crr.ca/divers-files/en/pub/rep/ ePubRepSioLoo.pdf.

Statistics Canada (2009). Women in Canada: A genderbased statistical report (Catalogue No. 89-503-XWE). Retrieved from http://www.statcan.gc.ca/pub/89. 503-x/2005001/chap8-eng.htm.

Statistics Canada. (2009). The incarceration of Aboriginal people in adult correctional services. (Catalogue No. 85-002-XWE). Retrieved from http://www.statcan. gc.ca/pub/85-002-x/2009003/article/10903-eng. htm\#a5.

Statistics Canada. (2006). Aboriginal people as victims and offenders. The Daily, Tuesday June 6, 2006. Retrieved from http://www.statcan.gc.ca/dailyquotidien/060606/dq060606b-eng.htm.

Statistics Canada. (2006). Violence against women: Statistical trends. The Daily, Monday October 2, 2006. Retrieved from http://www.statcan.gc.ca/ daily-quotidien/061002/dq061002a-eng.htm.

Taylor-Butts, A. (2003/04). Canada's shelters for abused women. Juristat Canadian Centre for Justice Statistics, 25(3). Retrieved from http:// ywcacanada.ca/data/research_docs/00000035. pdf.

Titley, B. E. (1986). A narrow vision: Duncan Campbell Scott and the administration of Indian Affairs in Canada. Vancouver, BC: University of British Columbia Press.

Weingarten, K. (2004). Witnessing the effects of political violence in families: Mechanisms of intergenerational transmission and clinical interventions. Journal of Marital and Family Therapy, 30(1), 45-59. doi: 10.1111/j.1752-0606.2004. tb01221.x. 